\title{
Modern-day slavery, human rights and the sex industry
}

\author{
Robert Chrismas* and Brandi Chrismas ${ }^{\dagger}$
}

\begin{abstract}
This article explores the sex industry in Canada as modern-day slavery and an ongoing violation of basic human rights. Some argue that the sex industry is something that women or children choose to do as a legitimate profession, and others argue that they are exploited and manipulated by other people for indebtedness, for clothing, food, shelter or to support substance or alcohol addictions. How should the laws around sex trafficking and sexual exploitation be designed? The government could be in a position to legally ensure dignity and human rights protection for those engaged in selling sex. This paper highlights the perspectives of survivors of the sex industry as they describe heart-wrenching experiences that include torture, physical threats, psychological fear, and manipulation. As the public discourse grows around this ongoing scourge, momentum for change is also growing. There have been numerous efforts to address, disrupt, and end this social scourge. Our awareness of modern-day sex slavery atrocities seems to coincide with a greater sense of respect for fundamental human rights and a desire to protect them.
\end{abstract}

Key Words Sexual exploitation; laws; protection; sex-industry survivors; public discourse; dignity; Canada; abuse.

\section{INTRODUCTION}

Human trafficking for forced sex is a massive worldwide industry that is growing despite ever increasing efforts, cross-sectoral resources, and financial investments over recent decades. Prostitution has historically been seen as a socially acceptable crime that women commit to fulfill a need that many argue will always exist. However, our universal understanding has begun to shift from one of women selling sex as a "trade" that they choose voluntarily to a form of modern-day slavery that women and girls are most often forced into.

Some have argued that women need the protection of government to do this work freely, protected by the law. Indeed, many choose it as their profession. Many, however, are brought into it as children, against their free will. Many are targeted and exploited for profit by traffickers who make a great deal of money through criminal enterprise. Historically, "prostitutes" were viewed as criminals. Much of the discourse, in the literature and among law enforcement and the public across North America, now views sex-industry workers more as victims. Hence, we argue that the law should protect those most vulnerable as a first priority. This paper explores the sex industry in Canada as modern-day slavery and an ongoing violation of basic human rights.
Sexually exploited women and youth are physically and socially isolated, coerced, threatened, and tortured. All of these are forms of oppression as defined in the Universal Declaration of Human Rights (Canadian Women's' Foundation, 2014). In the Canadian context, the sex industry often involves survival sex, which includes impoverished women selling sex as they struggle to feed addictions, eat, and keep a roof over their heads (Chrismas, 2020).

Significant events have driven a national agenda to curb the sex industry in Canada in recent years. The Oppal inquiry into the Pickton mass murder case in British Columbia highlighted that people selling sex were historically seen as expendable (Oppal, 2012). It signalled changes in policing and the way missing persons cases were prioritized and investigated across Canada (Chrismas, 2013). Canada's Missing and Murdered Indigenous Women and Girls Inquiry later recognized that sexindustry survivors have rights to safety, security, and dignity that need protecting (Chrismas, 2020).

\section{AN AGE-OLD PROBLEM THAT IS GROWING}

Sexual exploitation and sex trafficking affect people in every country in every corner of the world (UNODC, 2014). Internationally, the industry is estimated to generate US\$99 billion

Correspondence to: Brandi Chrismas, E-mail: Brandichrismas95@gmail.com; Robert Chrismas, E-mail: robertwchrismas@hotmail.com

To cite: Chrismas, R., \& Chrismas, B. (2021). Modern-day slavery, human rights and the sex industry. Journal of Community Safety and Well-Being, 6141, 179-183. https://doi.org/10.35502/jcswb.212

(C) Author(s) 2021. Open Access. This work is distributed under the Creative Commons BY-NC-ND license. For commercial re-use, please contact sales@sgpublishing.ca. geUbLISHING Published by SG Publishing Inc. CSKA Official publication of the Community Safety Knowledge Alliance. 
yearly for organized criminal traffickers (Nelson, 2014). The United Nations reports that the problem in most regions of the world is worsening despite the massive resources that have been invested in an attempt to interrupt it (INODC, 2014). The Palermo Convention brought together 147 countries and acknowledged the seriousness of sexual exploitation and human trafficking internationally, highlighting the need for improved collaboration to combat it (Buttigieg, 2015).

The horrors of human sex trafficking and its continued violation of human dignity are accessible through the narratives of young women who have survived it (Chrismas, 2017). Following is one Canadian story. Pseudonyms are used throughout, to protect the identities of the survivors.

Ashley: From a survivor's view, I was first victimized at the age of 15 . I was groomed and coerced into entering the sex trade, and then to selling myself on Ellice and Home. All the money I made went to drugs. I was then introduced to an older man who pretended he was my boyfriend. He had me working out of an older girl's apartment who was out of town. I was advertised on the Internet and I would see many men a day there. He said he was keeping all the money and that I would get a car, my own condo, clothes. He bought me jewellery, but I didn't see any of the money. Then I ended up moving from Winnipeg to Vancouver, and back to Winnipeg to an abusive dangerous predator, and then to Toronto, where I was with a very controlling abusive predator who actually sold me. I was in jail and I had a surety, and I guess he had had enough of me, so he essentially sold me to another predator who ended up being murdered. He was shot in the head after which I returned to Winnipeg. Then when I came back to Winnipeg, I was trying to get help for my addictions, and I had ended up getting a big settlement from a lawsuit I had in Vancouver. And I wasn't able to manage the money, and I felt so hopeless, so much guilt, and so much shame that I jumped off of the Maryland Bridge. I landed on the ice. I broke my back and my legs, and my feet were crushed. So, I spent six months in the hospital rehabilitating from that. And from then I still was entrenched in the sex trade. That's all I had known my whole teens and adult life. I had been brainwashed by these men into thinking that I needed them. So, I had a son and I lost him to CFS. The turning point really wasn't for me until I was pregnant with my daughter. (Chrismas, 2017, p. 110-111)

For most, it starts in childhood, when the trauma of abuse and neglect makes them vulnerable to being targeted. It is challenging for them to resist and even harder to escape due to limited alternative options in life (Chrismas, 2017).

Some have argued that human rights change; they are not "timeless, unchanging or absolute" (Donnelly, 2013). The idea of individual dignity historically only applied to small elite segments of society (Donnelly, 2013). A more contemporary perspective views all individuals as having value, and some basic human rights. The idea of vast economic disparity that was common in the past is becoming increasing unacceptable in the Global North. In Canada, much of the discourse has been around rectifying the colonial oppression of Indigenous peoples. The idea of some communities living with water advisories and poor housing is less tolerable than it was. Similarly, increasing awareness of children and young women being targeted and oppressed in the sex industry is less and less tolerable in the modern context.

\section{LANGUAGE IS IMPORTANT}

Terms such as "sex trade" and "prostitution" have significant implications in how the agency and self-determination of people engaged in it are viewed. Scholars have highlighted that the term "prostitute," for example, wrongly infers that someone willingly sells her/his body as a sexual service in exchange for money or drugs. While some do engage willingly in prostitution, for the vast majority the term sexual slavery better describes their lot. Nowadays, those who work in support of people who have been trafficked generally avoid those terms, favouring more respectful language that references survivors and their dignity. Hence, the term "sex-industry survivors" has been favoured by many (Chrismas, 2017).

\section{Human Trafficking vs. Smuggling}

Scholars have provided in-depth discussions on the differences between sex trafficking and human smuggling $\left(\mathrm{O}^{\prime}\right.$ Brien et al., 2013). The legal definitions of smuggling involve people being moved across national borders. In many cases, they voluntarily seek assistance to be smuggled, with the hope of gaining meaningful employment and a better life. Often, their hope is quashed as traffickers change their final destination to a life of servitude (Chrismas, 2013). Trafficking, on the other hand, is characterized by deception and force in order for organized criminals to gain financially by exploiting others. Sex trafficking implies the exploitation for money that so often occurs (Chrismas, 2020).

\section{Sex Trade vs. Slavery}

The term "sex trade" is politically incorrect and is now considered insensitive in most circles. It implies a willingness on the part of women and children participating in selling sex (Cook \& Courchene, 2006). Kelsie is a sex trafficking survivor who later dedicated her life to helping others escape. She explains the importance of language.

Kelsie: All of their stories are different. But for many reasons, multiple systems have failed them, and they end up doing sex. Some of our women don't even use "sex trade" because that indicates a choice, and we never had choices (Chrismas, 2017, p. 110).

She highlights that most people do not have a choice about entering the sex industry. Hence, it is not a profession they have chosen; rather, traffickers and poor life circumstances that make them less resilient have chosen them.

\section{Victim vs. Survivor}

A leader in Canada's national anti-trafficking strategy, Diane Redsky encourages the use of the term "survivor" over "victim." She states, "Experiential women/survivors will always refer to themselves as "survivors" if they are [currently] in it or not. Referring to them as victims is disrespectful as it removes their agency and free will" (Chrismas, 2017, p. 23). The term "survivor" respects the agency and dignity of people who 
have been trafficked and preserves the self-determination of people who thrive in spite of the challenges life has thrown at them. Scholars have warned us about the negative impact that labels can have (Said, 1979). Research has confirmed that, in many cases, people refuse to reach out for help for fear of being labelled a "prostitute" (Chrismas, 2017, p. 23).

\section{FREEDOM TO CHOOSE AND MODERN-DAY SLAVERY}

Some argue that women should be free to choose the sex industry as a legitimate profession and have their rights to do so protected in the law (Canada vs. Bedford, 2013). Others argue that any time a woman sells her body for money, she is likely being exploited and manipulated by pimps and sex predators (Meyers, 2014). My research in Manitoba found the latter in the majority of cases (Chrismas, 2017). Many are brought into it through manipulation and trickery, not realizing, at first, that they are on a path to being exploited.

Ashley, a sex-industry survivor, describes how she was sexually exploited and didn't realize it.

Ashley: I think to me it's all the same really. In my opinion, "prostitution" is "sexual exploitation" and a form of violence against women. No child says, "When I grow up, I want to be a prostitute. I want to be in the sex trade." I was a victim and like I didn't even identify — and this is what I think is a crucial point-I didn't identify as a victim because I didn't know what sex trafficking was. I didn't know what sexual exploitation was. (Chrismas, 2017, p. 23)

Ashley highlights the importance of education and awareness programs to reduce vulnerability at a young age.

Many activists, scholars, and policymakers now define sex trafficking as modern-day slavery (O'Brien et al., 2013). The United Nations Protocol to Prevent, Suppress, and Punish Trafficking in Persons (2014) defines slavery as

the recruitment, transportation, transfer, harbouring or receipt of persons, by means of threat or use of force or other forms of coercion, of abduction, of fraud, of deception, of the abuse of power or a position of vulnerability or of the giving or receiving of payments or benefits to achieve the consent of a person having control over another person for exploitation.

Some scholars have stressed that modern-day trafficking is slavery because it is an "assault on fundamental human dignity" (Venkatraman, 2003, p. 2).

Predators often use debt bondage, psychological manipulation, social isolation, and threats of violence to groom and exploit young girls to lure them into prostitution (Chrismas, 2020). Street-level activity is relatively easy for the police to enforce and prosecute; however, arresting exploited people does not solve the problem. The real challenge lies in prosecuting traffickers. There are no complainants; the victims won't report and most of the activity is now hidden on the Internet (Chrismas, 2020). Solving these deep social problems will require looking much deeper than what the police or any other service agency can do.

\section{PERFORMING SEX TO SURVIVE}

Recent research has found that many survivors engage in survival sex, to pay off indebtedness for clothing, food, shelter, street drugs, and protection (Chrismas, 2017). Kaitlin, who was trafficked in the sex industry for many years, describes the degrading and oppressive experience that is typical of many survivors' experiences.

Kaitlin: Usually with the gang members, they-, you know, they scare you up. And I remember I had one biker tell me that "You know what? I'm gonna [expletive]' have you locked in the basement. And no one's gonna know you're down there. Guys are gonna be coming from all over just to [expletive] you. And they're gonna be paying me, not you. They'll do whatever they want to you. [expletives]. And I remember I was crying I was so scared, "I'll do whatever you want." "They'll do whatever they want, but they'll pay me, not you." And then I was just, “Okay, I'll give you your money." It really scared me. I paid, doing what I had to do. And I just gave them all the money." (Chrismas, 2017, p. 116)

This account by Kaitlin depicts what can only be characterized as slavery and torture, according to The United Nations Protocol to Prevent, Suppress, and Punish Trafficking in Persons, Especially Women and Children (United Nations, 2014).

\section{CURBING THE SEX INDUSTRY AND PROTECTING HUMAN RIGHTS}

The 1979 United Nations Convention on the Elimination of All Forms of Discrimination Against Women urged countries worldwide to take measures and create laws against trafficking and sexual exploitation of women (United Nations, 1979). In 2005, Canada adopted the United Nations Protocol to Prevent, Suppress and Punish Trafficking in Persons, Especially Women and Children (United Nations, 2014). Signing these declarations signaled an intention by the Canadian government to act; however, real changes did not come until a decade later.

Canadian laws historically treated prostitution more as a nuisance than as oppression and violence against women. Vagrancy and bawdyhouse laws were designed to keep prostitution from being a public nuisance. Solicitation laws from 1972 and the communication laws from 1985 discouraged "prostitution" by keeping it out of public view. The Criminal Code of Canada prohibited communicating for prostitution in any place open to public view. These laws were designed to keep sex selling activity hidden from public sight, not for the safety of people performing sex acts (Smith, 2014).

The 2013 Supreme Court of Canada Bedford decision resulted from an appeal by three women who were charged with existing prostitution-related offences (Canada v. Bedford, 2014). They argued that the old laws were unconstitutional, as they impeded their ability to safely earn a living through selling sex for money and jeopardized their safety. The old laws prevented women from negotiating with customers to determine whether it were safe to perform sex acts with them for money. The Bedford decision ruled that the existing laws would stay in place for one year, at which time 
they would be struck down; this gave the government and police agencies in Canada one year to generate new strategies. Three broad and very different approaches have been considered around the world, as well as in Canada; they include the following: (1) abolition, (2) full legalization, and (3) limited legalization.

\begin{abstract}
Abolition
The abolition approach would prohibit prostitution altogether for both the seller and the buyer and at least legally ensure dignity and human rights protection for those engaged in selling sex. Many have argued that this would criminalize women and children who participate in the sex industry. This approach could victimize sexually exploited people with criminal records and exacerbate their already formidable social challenges. This strategy would be contrary to the changing beliefs around the oppressive nature of the sex industry.
\end{abstract}

\section{Complete Legalization}

Another broad approach is complete legalization, making neither purchasing nor providing sex for money illegal. In Germany, Australia, and the Netherlands, prostitution was previously legalized. Subsequent studies revealed that the trafficking of girls and young women increased with legalization (Kelly et al., 2009). This may be in part because legalization brings licensing and government oversight. This could further marginalize those deemed illegal by virtue of failed medical health checks or other bureaucratic requirements.

At a 2016 forum on sex trafficking and sexual exploitation at the University of Winnipeg, Gunilla Ekberg, a widely published Swedish Canadian lawyer and advocate for victims of sex trafficking, explained how legalized prostitution in Amsterdam had failed. An audit of the famous legalized prostitution district revealed that most of the women working there were being trafficked by organized crime. A study of human trafficking trends in 150 different countries has concluded that legalizing prostitution generally correlates with increased human trafficking (Cho et al., 2013).

\section{Limited Legalization: The Nordic Approach}

Limited legalization recognizes sex sellers as victims of exploitation by traffickers. This approach favours antiprostitution laws targeting traffickers and pimps and also arresting and sentencing the purchasers of sex. This is known as the "Nordic Model," employed in Norway and Sweden since 1999, with some reported success (Smith, 2014). The Nordic Model has three significant aspects, as follows: (1) a national public education campaign, raising awareness about the harms of sexual exploitation, (2) programs with enhanced support for people escaping the sex industry, and (3) stringent laws prosecuting traffickers and johns (the purchasers), and not the survivors (Smith, 2014). With the Nordic approach, sex-industry activity in Sweden reportedly dropped by up to 50 percent between 1999 and 2004 (Eckberg, 2004).

In December 2014, Canada's version of the Nordic Model was enacted as Bill C-36, The Protection of Communities and Exploited Persons Act (Department of Justice, Canada, Bill-C36, 2014). The Department of Justice reported at the time that, "Bill C-36 reflects a significant paradigm shift away from the treatment of prostitution as 'nuisance,' as found by the Supreme Court of Canada in Bedford, toward treatment of prostitution as a form of sexual exploitation that disproportionately and negatively impacts on women and girls" (Department of Justice Canada, Bill-C36, 2014, p. 3).

\section{INTERVENTIONS}

There are tangible strategies that can work to interrupt sexindustry exploitation. They include recognizing that people trafficked in the sex industry are intersectionally challenged and need flexible supports that meet their needs. This requires a systemic focus on resources and improved training and education for all involved.

\section{Trauma-Informed Approaches}

Research has found that vulnerability to sexual exploitation involves the following factors: (1) being female, (2) being poor, (3) having a history of violence or neglect, (4) having a history of child sexual abuse, and (5) having a low level of education (Canadian Women's Foundation, 2014). Eighty-two percent of women in the Canadian sex industry experienced sexual abuse or general abuse as a child prior to being recruited into the sex industry (McIntyre, 2012). Other studies have confirmed high correlations between childhood sexual abuse and later childhood exploitation in the sex industry (Klatt et al., 2014). These findings indicate off-ramps and opportunities for intervention.

People who have been trafficked often suffer from multiple layers of challenges, including deep trauma and substance abuse. Caregivers must meet each of these intersectionally challenged individuals where they are. Trauma cannot be treated, for instance, through cognitive therapy, when a person is suffering from severe substance abuse. Systemic resources must be tailored and adjusted for each unique person and their individual needs (Chrismas, 2020).

\section{Education and Training}

Research has identified that there is an urgent need for more education and awareness. Children need to be more aware of lurking predators and how to avoid them. Professionals in law enforcement, social work, education, and health care all need greater awareness of what trafficking looks like and how to intervene when they see the signs. Education is also a key component in addressing the market. The customers have been found to respond well to awareness training, such as john schools, which have been used in many regions across North America. More research is required to find the most effective balance of education and enforcement in order to achieve the optimum deterrence of the market (Chrismas, 2017).

\section{Collaboration}

A key finding in recent research is the need for more effective partnerships and collaboration between the federal, provincial, municipal, and Indigenous governments. Also, there needs to be improved coordination of existing government and non-government support agencies. They often provide similar services and fight for the same limited pot of funds. More efficiency could be achieved if provincial governments, which are responsible for services such as law enforcement 
and child welfare, played a more active role in coordinating the system (Chrismas, 2013; 2017; 2020).

\section{CONCLUSION}

Survivors of the sex industry describe heart-wrenching experiences that include torture, physical threats, psychological fear, and manipulation. These dynamics definitively reveal the industry, for many, as modern-day slavery. Many complex issues lead women and girls to be sexually exploited. The solutions and opportunities to disrupt it are equally problematic. It seems that our historical tolerance for the sex industry has left modern society in a position of having ample opportunities to improve.

As the public discourse grows around the sex industry, momentum for change is also growing. We, as a society, have devoted massive resources and considerable public attention to disrupting this tragic social menace. Our awareness of the atrocities of modern-day sex slavery seems to coincide with a greater sense of and desire to respect and protect people's fundamental human rights. With a growing awareness of these injustices, we have a chance to improve our culture with a more profound sensitivity to the value, dignity, and human rights of every citizen and the need to prioritize them.

\section{CONFLICT OF INTEREST DISCLOSURES}

The authors declare that there are no conflicts of interest.

\section{AUTHOR AFFILIATIONS}

*Brandi Alexandra Chrismas, (MA expected, 2022), Arthur V. Mauro Institute for Peace and Justice, University of Manitoba, Winnipeg, MB, Canada; ${ }^{+}$Robert Chrismas, MPA, 2009, University of Winnipeg, and Ph.D., 2017, Arthur V. Mauro Institute for Peace and Justice, University of Manitoba, Winnipeg, MB, Canada.

\section{REFERENCES}

Buttigieg, F. (2015). Human trafficking, other forms of exploitation and prevention policies. Government of Canada's National Crime Prevention Center (NCPC).

Canada (Attorney General) v. Bedford, 2013 SCC 72. http://scc-csc.lexum. $\mathrm{com} / \mathrm{scc}-\mathrm{csc} / \mathrm{scc}-\mathrm{csc} / \mathrm{en} / \mathrm{item} / 13389 /$ index.do

Canadian Women's Foundation. (2014). One year later: Working together to end sex trafficking in Canada. https://canadianwomen.org/blog/ one-year-later-working-together-end-sex-trafficking-canada/

Cho, S.Y., Dreher, A., \& Neumayer, E. (2012) Does legalized prostitution increase human trafficking? World Development, 41, 67-82.

Chrismas, R. (2020). Sex industry slavery: Protecting Canada's youth. Toronto, ON: University of Toronto Press.

Chrismas, R. (2017). Modern day slavery and the sex industry: Raising the voices of survivors and collaborators while confronting sex trafficking and exploitation in Manitoba, Canada. Posted at MSpace, University of Manitoba.

Chrismas, R. (2013). Canadian policing in the 21st century: A frontline officer on challenges and changes. Montreal, QC: McGill-Queen's University Press.
Cook, R., \& Courchene, D. (2006). Preventing and eradicating the abuse of our children and youth: Regional team development. The Manitoba Association of Friendship Centers.

Department of Justice Canada. (2014). Bill C-36, An Act to amend the Criminal Code in response to the Supreme Court of Canada decision in Attorney General of Canada vs. Bedford and to make consequential amendments to other Acts (Protection of Communities and Exploited Persons Act). Accessed October 2020. https://www. parl.ca/DocumentViewer/en/41-2/bill/C-36/first-reading\#3

Donnelly, J. (2013). Universal human rights in theory and practice. Ithaca, NY: Cornell University Press.

Eckberg, G. (2004). The Swedish law that prohibits the purchase of sexual services: Best practices for prevention of prostitution and trafficking in human beings. Violence Against Women, 10(10), 14.

Kelly, L., Coy, M., \& Davenport, R. (2009). Shifting sands: A comparison of prostitution regimes across nine countries. Child \& Women Abuse Studies Unit, London Metropolitan University, 40-43.

Klatt, T., Cavnerb, D., \& Egan, V. (2014). Rationalising predictors of child sexual exploitation and sex-trading. Child Abuse \& Neglect, $38,252-260$

Mclntyre, S. (2012). Buyer beware: A study into the demand side of the sexual exploitation industry. Accessed October 2020. https://www. deslibris.ca/ID/236955

Meyers, D. T. (2014). Feminism and sex trafficking: Rethinking some aspects of autonomy and paternalism. Ethic Theory Moral Practice, $17,427-441$

Nelson, J. (2014, May 20). Modern-day slavery generates billions: UN report. The Globe and Mail. https://www.theglobeandmail. com/report-on-business/international-business/modern-day-slaverygenerates-billions-according-to-new-report/article18768332/

O'Brien, E., Hayes S., \& Carpenter B. (2013). The politics of sex trafficking: a moral geography. New York, NY: Palgrave Macmillan.

Oppal, W. (2012). Forsaken: The report of the missing women commission of inquiry. Library and Archives Canada Cataloguing in Publication, British Columbia. Accessed: October 2020. https://www2.gov. bc.ca/assets/gov/law-crime-and-justice/about-bc-justice-system/ inquiries/forsaken-es.pdf

Said, E. (1979). Orientalism. New York, NY: Random House.

Smith, J. (2014). The tipping point: Tackling the demand for prostituted/ trafficked women and youth. https://www.yumpu.com/en/document/ $\mathrm{read} / 46632230 /$ the-tipping-point-mp-joy-smith-feb-12-2014

UNODC. (2014). Global report on trafficking in persons 2014. https:// www.unodc.org/documents/data-and-analysis/glotip/GLOTIP_ 2014_full_report.pdf

United Nations. (2014). Protocol to prevent, suppress and punish trafficking in persons, especially women and children. United Nations Treaty Collection. https://www.ohchr.org/en/professionalinterest/pages/ protocoltraffickinginpersons.aspx

United Nations. (1979). The 1979 Convention on the elimination of all forms of discrimination against women. www.un.org/womenwatch/ daw/cedaw/text/econvention.htm\#intro

Venkatraman, B. A. (2003). Human trafficking: A guide to detecting, investigating, and punishing modern-day slavery. The Police Chief, $70(12), 1-8$. 